\title{
Research on Analysis and Countermeasures of Occupation Inadaptability of College Students Caused by Lacking Responsibility Consciousness
}

\author{
Hui Su \\ Zhengzhou University of Aeronautics \\ Zhengzhou, China 450046
}

\begin{abstract}
Because of the rapid development of market economy and transformation of society as well as the influences of western culture and values, many college students pay too much attention to self interest and realistic utility and lack responsibility consciousness, which cause the worries of many employers. It makes them have weak ability of occupational adaptability, appear the phenomenon of frequent job-hopping and their career development is limited. This article mainly explores and researches the manifestation that lacking responsibility consciousness leads to occupation inadaptability of college students and its promotion strategy.
\end{abstract}

Keywords-responsibility consciousness; occupation inadaptability; promotion strategy

\section{INTRODUCTION}

Because of the rapid development of market economy and transformation of society as well as the influences of western culture and values, many college students pay too much attention to self interest and realistic utility and lack responsibility consciousness, especially lack group consciousness and sense of social responsibilities, which cause the worries of many employers. This kind of phenomenon makes them have weak ability of occupational adaptability, appear the phenomenon of frequent job-hopping and their career development is limited. Therefore, it is necessary to explore and research on manifestation that lacking responsibility consciousness leads to occupation inadaptability of college students and how to improve sense of responsibilities of college students.

\section{SENSE OF RESPONSIBILITY AND OCCUPATIONAL ADAPTABILITY}

\section{A. Sense of Responsibility}

The so-called responsibility refers to things that one should do, namely: undertake tasks that one should undertake, accomplish missions that one should accomplish and do jobs that one should do, such as perform duties and responsibilities and fulfill tasks. Responsibility not only embodies mentality, attitude, principles, style habits and thinking of a person, but also embodies the mind, pattern and ambition of a person; as well as embodies the mission, life space and pursuit of a person. The so-called responsibility consciousness is a kind of self-awareness and refers to the psychological feature that a person clearly knows what is responsibility and consciously and carefully perform duties and transform responsibility into action.

\section{B. Occupational Adaptability}

Occupational adaptability refers to the ability of occupational adaptability, including: thinking adaptability, moral adaptability, health adaptability, target adaptability, attitude adaptability, learning adaptability, skills adaptability and interpersonal adaptability, and it is the comprehensive adaptive capacity of a person for one occupation. Thinking adaptability refers to objective and dialectical positive thinking ability. Moral adaptability refers to the ability to abide by social code of conduct and standard. Health adaptability refers to the ability to keep healthy and bear the heavy work. Target adaptability refers to the ability to be determined and develop directionally. Attitude adaptability refers to the ability to use highly-developed sense of responsibility to treat and pursue an occupation. Learning adaptability refers to the ability to grasp knowledge and learn to meet practical needs. Skills adaptability refers to the professional technical capability to finish own work. Interpersonal adaptability refers to the ability to cooperate with others harmoniously and handle all kinds of relationships.

\section{Relationship between the Two}

The core of occupational adaptability is "sense of responsibility". "Sense of responsibility" or "responsibility consciousness" is the core implicit element of attitude, determines professional attitude of a person and then determines his occupational adaptability. A person with strong responsibility consciousness has strong ability of occupational adaptability and vice versa.

\section{LACKING RESPONSIBILITY CONSCIOUSNESS LEADS TO THE PHENOMENON THAT COLLEGE STUDENTS HAVE OCCUPATION INADAPTABILITY}

Responsibility is a kind of ability and outclasses ability. It is a kind of spirit as well as character and morals. Responsibility refers to that people can undertake the work that they do not like without complaints and do it very well 
carefully. People who can shoulder responsibility, be good at shouldering responsibility and be brave to shoulder responsibility are the people who can be trusted by others. Lev Tolstoy once said, "If a person does not have passion, he will accomplish nothing. The base point of passion is exactly the responsibility". Victor Phelan Kerr once also said, "Everyone is inquired by life, while he can only use his life to answer this question and reply life as a responsible person. Therefore, "the most important nature of human existence is that people can be responsible". A person with sense of responsibility has good learning attitude and professional dedication and strong social adaptability and is respected and adored by people; a person with sense of responsibility will try to find some ways to overcome difficulties; a person with sense of responsibility will consciously safeguard interests of the organization. Among many of the global 500 companies, "responsibility" is the most critical idea and value. For example, in IBM, the value that each employee must fulfill is "the morality that one should forever keeps in interpersonal communication is strong responsibility consciousness". In Microsoft, "responsibility" runs through the behavior of each employee. In HP (Hewlett Packard), people without idea of responsibility will be dismissed. Obviously, responsibility consciousness is extremely important for a person, especially for professionals. However, many contemporary college students seriously lack responsibility consciousness. It leads to the fact that they cannot be responsible for themselves, others and job and society. Therefore, they have weak occupational adaptability. It mainly shows in the following aspects:

\section{A. Perfunctory Attitude}

Responsibility consciousness determines the attitude toward work. But in practical work, many college students have the attitude of "carelessness", lack preciseness in work and have no strong responsibility consciousness. Therefore, they are criticized by leaders frequently. However, they do not carefully reflect on themselves but think it is small thing and has no relationship with the whole situation, and there is absolutely no need to have strict requirements. However, they hardly realize "a miss is as good as a mile". Sometimes, a small mistake in work may bring enormous losses for the whole society. For example, a financial staff makes a mistake on decimal point when handling accounts of the company, which leads to the fact that the company loses million yuan.

\section{B. Always Complain}

Some college students always complain in work, because they are assigned to ordinary posts that they think these posts are not in important departments. They think the work unit "wastes their talent on a petty job". Therefore, they lack passion in work and complain to colleagues and friends. They do not know that they need to temper themselves when they are just hired. It is extraordinary to do a good job in ordinary work. They will be promoted to complete simple things. Many successful people start from grass-roots and ordinary work.

\section{Be Afraid of Facing the Difficulty}

A person should have the "spirit of facing difficulties" and be brave to "shoulder the responsibility that they should bear".
Only in this way can they do a good job in work and do things right. However, some college students lack "spirit of facing difficulties". In work, they make excuses and pass the buck when facing big troubles instead of find reasons of their own. It makes many enterprises dislike this kind of college students and always "fire them".

\section{Cannot Correctly View Obedience and Service}

The fondness and excessive tolerance from family and protection from schools make some college students form selfcentered value. When they get employed, face new crowd and environment, they cannot accomplish role change and attitude adjustment. Therefore, they are always at loose ends. They cannot regard obedience and service as a part of position statement and always do things according to their ideas. They are very capricious. Therefore, they cannot deal with relations among them and leaders, colleagues as well as clients.

\section{E. Frequent Job-hopping}

Nowadays, it is very common for college students to change jobs. Some of them change several jobs in one year, which make many employers "dissatisfy". They have many reasons to change jobs, for example: they are criticized because they make mistakes in work, they are unable to get along with the boss, they love current job, etc. In reality, we see through the appearance of job-hopping to perceive the essence is that college students lack responsibility consciousness. It is difficult for people who choose to escape because of various reasons to adapt to all kinds of occupation, let alone achieving great success. "Loyalty index" is a standard that many enterprises pay much attention to. A person can better adapt to his position only through successfully completing the work of his own, and then get closer to success.

\section{STRATEGIES TO IMPROVE RESPONSIBILITY CONSCIOUSNESS OF COLLEGE STUDENTS}

To sum up, responsibility consciousness are extremely important for college students to improve the ability of occupational adaptability. Therefore, it is necessary to try to improve responsibility consciousness of college students.

\section{A. Improve Responsibility Consciousness of College Students in Work}

On one hand, teachers shall guide college students to know clearly about the relationship between professional knowledge and future profession and encourage them to work hard at professional knowledge. On the other hand, teachers shall encourage students to read more books, especially books of relevant famous person, such as the Great Learning, the Doctrine of the Mean, and the Analects of Confucius. Reading books makes us wise and improve understanding level of a person. Reading more books of relevant famous person can improve responsibility consciousness of college students imperceptibly. 
B. Improve Responsibility Consciousness of College Students in Life

Start from small details and develop good living habits of college students. Train college students about sense of time; make them take time as coordinate in doing any thing. Make college students get used to shouldering responsibilities. Let them realize their responsibilities in doing any work or task, be brave to shoulder responsibility; find ways and positively take actions and pay attention to each detail for shouldering responsibilities. They shall not regret before delivering the result.

\section{Improve Responsibility Consciousness of College Students in Group Activities}

Class or club activities can make college students deeply know that the honor of the group has relationship with each person. The whole group will make certain achievements if all members in the group work in unity and help one another and make joint efforts, be equal and friendly. In the process of participating in these activities, the collective responsibility consciousness of students is cultivated. It will greatly improve the cultivation of team awareness of college students in workplace.

\section{Improve Responsibility Consciousness of College Students in Practical Activities}

The learning of college students cannot stay on books. They should apply their knowledge through social practice activities. They can better contact with society and understand national conditions, voluntarily serve the society and gradually develop social responsibility consciousness through participating in volunteer service and practical activity of "a program under which officials, doctors, scientist and college students go to the countryside to spread scientific and literacy knowledge and offer medical service to farmers".

\section{CONCLUSION}

Responsibility is the basis to cultivate person and start career. Many enterprises regard "loyalty index" or "sense of responsibility" as an important standard to employ person. Occupation inadaptability of college students is caused by lacking responsibility consciousness. Therefore, students can better adapt to the occupation undertook by them in the future only through cultivating and improving their responsibility consciousness in learning, life, group activities and social practice activities.

\section{REFERENCES}

[1] Ren Zhanzhong. Practice Guiding for College Students, Beijing: Beijing Jiaotong University Press, 2013

[2] Ren Zhanzhong, Chen Yongli. Guidance to Occupational Adaptation of College Students, Beijing: Beijing Jiaotong University Press, 2012

[3] Ren Zhanzhong, Xiong Yizhi. Expansion of Occupation Adaptability of College Students, Beijing: Beijing Jiaotong University Press, 2012

[4] Wang Yunbiao. College Student Internship and Employment Guidance, Beijing: Peking University Press, 2007 